\title{
MODEL PENINGKATAN LOYALITAS PELANGGAN DENGAN PENGUJIAN TERHADAP SERVICESCAPE, KUALITAS PELAYANAN DAN KEPUASAN PELANGGAN
}

\author{
Marno Nugroho \& Sahrul Romadhon \\ Program Studi Manajemen, Fakultas Ekonomi, Universitas Islam Sultan Agung Semarang \\ E-mail: marnonugroho@unissula.ac.id
}

\begin{abstract}
ABSTRAK
Era globalisasi, perkembangan dunia fashion dengan berbagai macam model dan desain meningkat sangat pesat. Kondisi ini memicu adanya siklus perubahan gaya berbusana yang dinamis, terutama pada industri fashion jam tangan. Selain untuk penunjuk waktu jam tangan juga dapat memberi kesan tersendiri untuk para pemakainya. Penelitian ini menguji peran pemasar dalam mengoptimalkan strategi guna mendapatkan kepuasan dan loyalitas pelanggan. Metode pengambilan sampel dilakukan dengan menggunakan teknik non probality sampling dengan cara purposive sampling. Dengan jumlah pesaing yang terbilang besar, maka fokus persaingan tidaklah cukup hanya pada kualitas produk dan harga. Perusahaan membutuhkan strategi yang inovatif untuk bertahan dan memenangkan persaingan. antara lain strategi meningkatkan kualitas pelayanan dan mengatur ulang servicescape dalam hal ini berkaitan dengan kepuasan pelanggan dan loyalitas pelanggan.
\end{abstract}

Kata Kunci : kualitas pelayanan, servicescape, kepuasan pelanggan, loyalitas pelanggan

\begin{abstract}
In the era of globalization, the development of the fashion world with a variety of models and designs is increasing very rapidly. This condition has triggered a cycle of changing the style of dress that is dynamic, especially in the watch fashion industry. In addition to referring to the time the watch can also give a distinctive impression to the wearer. The sampling method is carried out using non probability sampling techniques by means of purposive sampling. By wearing a watch we can look more elegant. With a fairly large number of competitors, triggering the clock shop to focus on product quality and price competition, but the competition is not enough because there are still many aspects that can be used by the clock store to win the competition and become a market leader. Innovative strategies are needed to survive and win the competition, including strategies to improve service quality and rearrange Servicescape in this regard with regard to customer satisfaction and customer loyalty.
\end{abstract}

Keywords : Service Quality, Servicescape, Customer Stisfaction, Customer Loyality 


\section{Marno Nugroho}

\section{Sahrul Romadhon}

\section{PENDAHULUAN}

Pada era globalisasi, perkembangan dunia fashion dengan berbagai macam model dan desain meningkat sangat pesat. Ditambah hadirnya beberapa platform social media turut membantu persebaran gaya berbusana baik ditanah air maupun di mancanegara. Kondisi ini memicu adanya siklus perubahan gaya berbusana yang dinamis, terutama pada industri fashion jam tangan. Bagi sebagian orang jam tangan merupakan sesuatu yang dinilai ketinggalan jaman dan sudah ditinggalkan, namun sebagian besar orang juga mengerti seberapa pentingnya waktu.Selain untuk penujuk waktu jam tangan juga dapat memberi kesan tersendiri untuk para pemakainya. Dengan mengenakan jam tangan kita dapat terlihat lebih elegan, selain itu banyak para pemasar dari perusahaan-perusahaan besar menilai jam tangan sebagai nilai tambah untuk meningkatkan nilai jual dari penampilan mereka.

Diluar aspek globalisasi, persaingan yang ketat juga menjadi ancaman tersendiri pada toko jam tangan, pasalnya menurut BPS Kota Semarang terdapat lebih dari 100 unit toko yang menjual jam tangan mulai dari yang ekonomis sampai yang bernilai tinggi dan bersertifikat resmi, seperti Alexandre Christie, Jaque Martin, Swiss Army, dan lain sebagainya.

Dengan kondisi persaingan yang semakin ketat ini, para pengusahaToko Jam di Kota Semarang dituntut untuk dapat bertahan dan menjaga eksistensinya.Dengan jumlah pesaing yang terbilang besar, memicu toko jam untuk berfokuskan persaingan kualitas produk dan harga, namun persaingan tersebut tidaklah cukup karena masih banyak aspekaspek yang dapat dimanfaatkan oleh toko jam untuk memenangkan persaingan dan menjadi market leader. Dibutuhkan strategi yang inovatif untuk bertahan dan memenangkan persaingan, antara lain strategi untuk meningkatakan kualitas pelayanan dan mengatur ulang Servicescape dalam hal ini berkaitan dengan kepuasan pelanggan dan loyalitas pelanggan.

Loyalitas pada dasarnya dapat didefiniskan sebagai kesetiaan seseorang terhadap suatu hal. Loyalitas pelanggan adalah komitmen pelanggan untuk bertahan secara mendalam untuk melakukan pembelian ulang atau berlangganan kembali produk atau jasa yang dipilih secara konsisten di masa yang akan datang, meskipun pengaruh situasi dan usahausaha pemasaran mempunyai potensi untuk menyebabkan perubahan perilaku. Beberapa pelanggan dari suatu Toko jam berpendapat bahwa mereka ingin melakukan pembelian ulang pada toko jam tersebut, namun ada juga yang mengatakan bahwa mereka hanya kebetulan lewat dan melakukan pembelian di toko jam tersebut karena mereka memiliki tempat langganan mereka sendiri. Kondisi tersebut tentu membawa pengaruh yang tidak baik pada perkembangan toko jam. Mempertahankan pelanggan adalah hal yang dapat 
membawa dampak postif dimasa yang akan datang, dengan kata lain strategi ini merupakan strategi jangka panjang. Terdapat beberapa upaya untuk menjaga dan mempertahankan pelanggan. Diantara lain dengan meningkatkan kualitas karyawan untuk melayani pelanggan dan membuat Servicescape semenarik mungkin.

Dalam hal ini yang dimaksud meningkatkan kualitas pelayanan untuk menciptakan kepuasan pelanggan adalah bagaimana pihak toko mampu memberikan pelayanan yang sesuai dengan ekspektasi pelanggan, cepat, dan tepat sehingga mampu mewakili integritas toko tersebut. Selain melayani pelanggan dengan cepat, pihak toko juga harus mengerti seberapa pentingnya untuk memahami apa yang diinginkan oleh pelanggan, agar pelanggan mendapatkan kepuasan yang optimal.

Selain meningkatkan kualitas pelayanan strategi atas bagaimana memaksimalkan aspek Servicescape dapat menjadi salah satu strategi yang tersedia bagi para pengusaha riteltoko jam untuk memenangkan persaingan di pasar. Dengan memaksimalkan aspek Servicescape pelanggan akan melihat nilai tambah pada toko jam tersebut. Memaksimalkan Servicescape sendiri dapat diartikan bagaimana pihak toko mengatur sedemikian rupa tata letak fisik agar mampu menciptakan perasaan nyaman, menarik, dan rapi sehingga mampu membuat para pelanggan betah untuk berlama-lama didalam toko. Dengan bertambahnya kontribusi aspek Servicescape ini pelanggan akan mendapatkan kepuasan tersendiri dalam melihat keindahan dan kerapian lingkungan fisik dari toko.

Bagi Toko jam kepuasan pelanggan merupakan salah satu tolok ukur atas strategi yang diterapkan pada toko tersebut. Kenyataan ini bisa dilihat, bahwa ada beberapa hal yang dapat memberikan kepuasan pelanggan yaitu nilai total pelanggan yang terdiri dari nilai produk, nilai pelayanan, nilai personal, nilai image atau citra, dan biaya total pelanggan yang terdiri dari biaya moneter, biaya waktu, biaya tenaga, dan biaya pikiran Kotler dalam Pangkey (2013). Jika strategi tersebut efektif, maka akan memberikan kepuasan yang optimal kepada pelanggan.

\section{Kualitas Pelayanan, Servicescape, Kepusan Pelanggan}

Ernani (2010) Kualitas pelayanan merupakan salah satu tolok ukur atas keberhasilan dalam memberikan jaminan atas kepuasan bagi pelanggan, melalui kulaitas pelayanan seorang pelanggan dapat memberikan penilaian secara obyektif dalam usaha menciptakan menciptakan kepuasan pelanggan. Kualitas pelayanan adalah keseluruhan ciri-ciri dan karakteristik dari suatu produk atau jasa dalam hal kemampuannya memenuhi kebutuhankebutuhan yang telah ditentukan atau bersifat laten, dengan menekankan pada orientasi pemenuhan harapan pelanggan untuk memperoleh kecocokan untuk pemakaian (fitness 


\section{Marno Nugroho}

\section{Sahrul Romadhon}

for use). Keinginan pelanggan adalah suatu prioritas bagi perusahaan yang harus dijadikan salah satu alat sebagai pengukur seberapa besar kinerja perusahaan, dengan cara melihat seberapa besarkah perusahaan menyediakan keunggulan dalam rangka memenuhi keinginan pelanggan-pelanggannya.

Ratminto dan Winarsih (2012) untuk dapat menyelenggarakan manajemen pelayanan yang baik, perusahaan harus mengelola momen kritis pelayanan, berempati pada pelanggan dan menghindari terjadinya ketidak sesuaian yang tidak diinginkan.

Lupiyoadi (2013) servicescpe adalah lingkungan fisik tempat layanan penyampaian produk atau jasa tersebut berada. Sedangkan menurut Pangkey (2013) Servicescape merupakan fasilitas fisik perusahaan yang digunakan untuk mempengaruhi perasaan pelanggan agar senang dan positif. Lovelock et al. (2010) berpendapat bahwa kondisi lingkungan fisik yang dialami oleh pelanggan memiliki peranan penting dalam membentuk pengalaman layanan dan memperkuat atau mengurangi kepuasan pelanggan.

Kotler et al. (2016) menyatakan bahwa kepuasan pelanggan adalah perasaan senang atau kecewa seseorang yang muncul setelah membandingkan antara kinerja produk atau jasa yang dipikirkan dengan kinerja yang diharapkan. Banyaknya perusahaan menitik beratkan pada kepuasan pelanggan yang tinggi karena hal ini akan mengikat pelanggan karena merasa puas akan pelayanan yang didapatnya.

Rismi dan Juni (2014) kepuasan pelanggan adalah presepsi dan perasaan senang atau kecewa yang dimiliki oleh pelanggan berdasarkan dari perbandingan kinerja produk atau jasa yang dikonsumsi dengan harapan yang dimiliki oleh pelanggan sebelum mengkonsumsi produk atau jasa tersebut.

Kepuasan pelanggan adalah pendorong utama bagi retensi dan loyalitas pelanggan. Sebagian besar pelanggan menitik beratkan kepuasannya semata-mata hanya pada dorongan harga, sedangkan sebagian pelanggan lainnya menitik beratkan kepuasan mereka kepada keputusan pembelian berdasarkan tingkat kepuasan produk dan jasa yang mereka butuhkan.

\section{Loyalitas Pelanggan}

Menurut Griffin dalam Hurriyati (2010) menyatakan bahwa "loyality is defined asa non random purchase expressed over time by some decision making unit". Berdasarkan definisi tersebut terlihat jelas bahwa loyalitas lebih ditujukan kepada suatu perilaku, yang ditunjukkan dengan pembelian rutin, didasarkan pada unit pengambilan keputusan. 
Sedangkan Tjiptono et al. (2012) berpendapat bahwa loyalitas pelanggan adalah komitmen pelanggan terhadap suatu merk, toko, atau pemasok berdasarkan sikap yang sangat positif dan tercermin dalam pembelian ulang yang konsisten.

Hurriyati (2010) berpendapat bahwa loyalitas pelanggan memiliki peran penting dalam sebuah perusahaan, mempertahankan mereka berarti meningkatkan kinerja keuangan dan mempertahankan ke langsungan hidup perusahaan, hal ini yang menjadi alasan utama bagi perusahaan dalam menarik dan mempertahankan pelanggannya.

\section{Kualitas pelayanan dan Kepuasan pelanggan}

Kotler et al. (2011) dalam Lumentut dan Palandeng (2014) mendefinisikan pelayanan sebagai setiap tindakan atau kegiatan yang dapat di tawarkan oleh suatu pihak kepada pihak lain, yang pada dasarnya tidak berwujud dan tidak mengakibatkan kepemilikan apapun. Tjiptono (2011) dalam Lumentut dan Palandeng (2014) mengemukakan bahwa kualitas pelayanan merupakan ukuran seberapa bagus tingkat layanan yang diberikan mampu sesuai dengan ekspektasi pelanggan atau tidak. Konsep kualitas pelayanan merupakan perbedaan antara harapan dan kenyataan yang dirasakan pelanggan terhadap pelayanan dari suatu perusahaan, dimana kualitas pelayanan merupakan salah satu komponen dari kepuasan pelayanan.Penalitian yang dilakukan oleh Lumentut dan Palandeng (2014) tentang fasilitas, Servicescape,kualitas pelayanan, pengaruhnya terhadap kepuasan pelanggan pada Mcdonald's Manado memper oleh kesimpulan bahwa kualitas pelayanan berpengaruh terhadap kepuasan pelanggan. Penelitian lain yang dilakukan oleh Masloman et al. (2014) menunjukan secara parsial variabel kualitas pelayanan berpengaruh positif terhadap variabel kepuasan pelanggan. Dari teori dan hasil penelitian terdahulu diatas diperoleh hipotesis sebagai berikut: H1: Kualitas pelayanan berpengaruh positif terhadap kepuasan pelanggan.

\section{Servicescape dan Kepuasan Pelanggan}

Lovelock dan Wirtz, (2011) dalam Yulianita dan Gitasiswhara (2013) Servicescapeadalah gaya dan wujud dari lingkungan fisik dan elemen-elemen eksperiental lainnya yang ditemukan oleh pelanggan ditempat jasa tersebut disampaikan. Kemampuannya untuk menciptakan kesan positif atau negatif terhadap masing-masing pancaindera menyebabkan makin banyak perusahaan memberikan perhatian penuh terhadap desain perusahaannya.

Selain itu Servicescape sangat penting untuk customer experience karena lingkungan tersebut memberikan tanda atau sinyal-sinyal tangible maupun intangible atas jasa atau produk yang ditawarkan kepada pelanggan (Yuliantina \& Gitasiswhara, 2013). 


\section{Marno Nugroho}

\section{Sahrul Romadhon}

Penelitian yang dilakukan oleh Masloman et al. (2014) tentang kualitas pelayanan dan Servicescape pengaruhnya terhadap kepuasan pelanggan pada Kentucky Fried Chicken MultimartRanotana Manado mendapatkan hasil bahwa Servicescape berpengaruh terhadap kepuasan pelanggan. Penelitian lain yang dilakukan oleh Cempaka et al. (2015) tentang pengaruh Servicescape terhadap kepuasan dan dampaknya pada loyalitas nasabah PT Bank Pembangunan Jawa Timur Tbk. Dimana disimpulkan bahwa Servicescape memiliki pengaruh secara positif terhadap kepuasan nasabah. Berdasarkan teori dan hasil penelitian terdahulu diatas diperoleh hipotesis sebagai berikut: H2: Servicescape berpengaruh positif terhadap kepuasan pelanggan.

\section{Kualitas pelayanan dan Loyalitas pelanggan}

Menurut Maharani (2010) mendefinisikan kualitas pelayanan adalah tingkat keunggulan yang diharapkan dan pengendalian atas tingkat keunggulan tersebut untuk memenuhi keinginan pelanggan. Kualitas pelayanan ditentukan oleh bagaimana tingkat kesesuaian antara pelayanan yang diberikan dan pelayanan yang diharapkan oleh pelanggan. Kualitas pelayanan menjadi salah satu ukuran atas keberhasilan dalam memberikan jaminan atas kepuasan bagi pelanggan, melalui kualitas pelayanan seorang pelanggan dapat memberikan penilaian secara obyektif dalam usaha menciptakan kepuasan pelanggan. Dari hasil penelitian terdahulu dan teori diatas maka diperoleh hipotesis sebagai berikut: H3: Kualitas pelayanan berpengaruh positif dan signifikan terhadap loyalitas pelanggan.

\section{Servicescape dan Loyalitas pelanggan}

Simpeh (2011) dalam Yuliantina dan Gitasiswhara (2013) mendefinisikan Servicescape sebagai penampilan luar dari perusahaan dan penting untuk menciptakan kesan pertama atau membangun harapan bagi pelanggan. Servicescape merupakan salah satu unsur yang harus didaya gunakan oleh perusahaan sehingga menimbulkan rasa nyaman, tentram, dan dapat meningkatkan hasil kerja yang baik untuk meningkatkan kinerja perusahaan tersebut. Penelitian yang dilakukan oleh Cempaka et al. (2015) tentang pengaruh Servicescape terhadap kepuasan dan dampaknya pada loyalitas pelanggan diperoleh hasil bahwa terdapat pengaruh positif antara Servicescape dan loyalitas pelanggan.

Penelitian lain yang dilakukan oleh Musriha (2011) yang memperoleh kesimpulan bahwa Servicescape berpengaruh posotif terhadap loyalitas nasabah Bank Mandiri Surabaya dapat diterima. Dari hasil penelitian terdahulu dan teori diatas ditari hipotesis sebagai berikut: H4 : Servicescape berpengaruh positif terhadap loyalitas pelanggan. 


\section{Kepuasan pelanggan dan Loyalitas pelanggan}

Harapan pelanggan merupakan salah satu faktor untuk mengukur kepuasan pelanggan. Dengan adanya harapan pelanggan yang meliputi pengalaman pada masa lalu pelanggan dapat mempengaruhi kepuasan pelanggan itusendiri terhadap suatu produk atau jasa yang dikonsumsinya. Penelitian yang dilakukan oleh Cempaka et al. (2015) tentang pengaruh Servicescape terhadap kepuasan dan dampaknya pada loyalitas pelanggan yang memperoleh hasil bahwa kepuasan nasabah secara parsial memiliki pengaruh terhadap loyalitas nasabah. Dari hasil penelitian terdahulu dan teori diatas maka ditarik sebuah hipotesis sebagai berikut:

\section{H5 : Kepuasan pelanggan berpengaruh positif dan signifikan terhadap loyalitas pelanggan.}

\section{Metode penelitian}

Populasi dalam penelitian ini adalah pelanggan yang membeli atau membeli produk dari Toko jam di Kota Semarang yang tidak diketahui jumlahnya. Metode pengambilan sampel dilakukan dengan menggunakan teknik non probality sampling dengan cara purposive sampling. Sugioyono (2001) menyatakan purposive samling adalah teknik penentuan sampel dengan pertimbangan atau kriteria tertentu. Adapun karakteristik tersebut adalah pelanggan yang pernah membeli produk jam tangan dari Toko Jam Star Watch, Davi Jam, dan Toko Jam Diana minimal sebanyak tiga kali pembelian, dan yang berumur 18 tahun keatas.

Kualitas Pelayanan (X1) adalah Kualitas pelayanan adalah keseluruhan ciri-ciri dan karakteristik dari suatu produk atau jasa dalam hal kemampuannya memenuhi kebutuhankebutuhan yang telah ditentukan atau bersifat laten, dengan menekankan pada orientasi pemenuhan harapan pelanggan untuk memperoleh kecocokan untuk pemakaian (Tjiptono et al. 2005). Memiliki indikator sebagai berikut :
1. Reliability.
2. Responsiveness.
3. Assurance.
4. Empathy.

Servicescape adalah gaya dan wujud dari lingkungan fisik dan elemen-elemen eksperimental lainnya yang ditemukan pelanggan di tempat jasa tersebut disampaikan. Lovelock dan Writz (2011) memiliki indikator sebagai berikut:

1. Kondisi ambient.

2. Pengaturan spasial.

3. Pengturan fungsional.

4. Simbol-simbol dan artefak. 


\section{Marno Nugroho}

\section{Sahrul Romadhon}

Kepuasan pelanggan adalah perasaan senang atau kecewa seseorang yang muncul setelah membandingkan antara kinerja produk atau jasa yang dipikirkan dengan kinerja yang diharapkan (Kotler et al., 2016). Memiliki indikator sebagai berikut:

1. Terpenuhinya harapan pelanggan.

2. Perasaan puas menggunakan produk.

3. Kepuasan terhadap Servicescape (lingkungan fisik).

4. Kepuasan terhadap kualitas pelayanan.

Loyalitas pelanggan adalah komitmen pelanggan terhadap suatu merk, toko, atau pemasok berdasarkan sikap yang sangat positif dan tercermin dalam pembelian ulang yang konsisten. (Tjiptono et al. 2012). Memiliki indikator sebagai berikut:

1. Melakukan transaksi ulang.

2. Merekomendasikan kepada orang lain.

3. Tidak ada keinginan pindah ke perusahaan lain.

4. Menggunakan produk sejenis.

Analisis regresi linier berganda digunakan untuk mengetahui seberapa besar pengaruh hubungan variabel kualitas pelayanan (X1), Servicescape (X2), kepuasan pelanggan (Y1), loyalitas pelanggan (Y2). Keempat, Menguji hipotesis yang digunakan dalam penelitian.

\section{HASIL DAN PEMBAHASAN}

\section{Pengujian Instrumen}

\section{Uji Validitas}

Semua indikator yang digunakan untuk mengukur variabel-variabel yang digunakan dalam penelitian ini mempunyai koefisien korelasi yang lebih besar dari $r_{\text {table }}=0,197$ (nilai $r$ tabel untuk $n=100$ ). Nilai signidikansi juga menunjukkan lebih kecil dari 0,05 . Sehingga semua indikator tersebut adalah valid.

\section{Uji Reliabilitas}

Semua variabel mempunyai koefisien Alpha yang cukup besar yaitu diatas 0,60 sehingga dapat dikatakan semua konsep pengukuran masing-masing variabel dari kuesioner adalah reliabel sehingga untuk selanjutnya item-item pada masing-masing konsep variabel tersebut layak digunakan sebagai alat ukur.

\section{Analisis Regresi dan Uji Hipotesis}


Tabel 1. Analisis Regresi Model 1 Coeficients ${ }^{\circ}$

\begin{tabular}{|c|c|c|c|c|c|}
\hline \multirow{2}{*}{ Model } & $\begin{array}{r}\text { Unst } \\
\mathrm{C}\end{array}$ & $\begin{array}{l}\text { ardized } \\
\text { ients }\end{array}$ & \multirow{2}{*}{$\begin{array}{c}\begin{array}{c}\text { Standardiz } \\
\text { ed } \\
\text { Coeficient } \\
\text { s }\end{array} \\
\text { Beta } \\
\end{array}$} & \multirow[t]{2}{*}{$t$} & \multirow[t]{2}{*}{ Sig } \\
\hline & B & Std. Error & & & \\
\hline (Constant) & 2.635 & 1.291 & & 2.041 & .044 \\
\hline Kualitas Pelayanan & .354 & .074 & .382 & 4.805 & .000 \\
\hline Service Scape & .461 & .080 & .457 & 5.750 & .000 \\
\hline
\end{tabular}

Sumber : Data Primer (2018)

Tabel 2. Analisis Regresi Model 2 Coeficients ${ }^{b}$

\begin{tabular}{|c|c|c|c|c|c|}
\hline \multirow{2}{*}{ Model } & \multicolumn{2}{|c|}{$\begin{array}{l}\text { Unstandardized } \\
\text { Coeficients }\end{array}$} & \multirow{2}{*}{$\begin{array}{c}\text { Standardiz } \\
\text { ed } \\
\text { Coeficient } \\
\text { s } \\
\text { Beta } \\
\end{array}$} & \multirow[t]{2}{*}{$\dagger$} & \multirow[t]{2}{*}{ Sig } \\
\hline & B & Std. Error & & & \\
\hline (Constant) & 3.264 & 1.313 & & 2.501 & .014 \\
\hline Kualitas Pelayanan & .188 & .082 & .210 & 2.299 & .024 \\
\hline Service Scape & .192 & .093 & .196 & 2.077 & .040 \\
\hline Kepuasan Pelanggan & .386 & .101 & .401 & 3.819 & .000 \\
\hline
\end{tabular}

Sumber : Data Primer (2018)

Dari pengolahan data menggunakan program SPSS 16.0, diperoleh hasil seperti yang ditunjukkan pada tabel 1 dan 2 yaitu :

a. Nilai koefisien regresi untuk variabel Kualitas pelayanan terhadap kepuasan pelanggan menunjukkan nilai positif sebesar 0,382 dengan sig sebesar 0,000. memberikan pengertian bahwa semakin baik kualitas pelayanan, maka berdampak pada tingginya kepuasan pelanggan terhadap produk tersebut.

b. Nilai koefisien regresi untuk variabel servicescapeterhadap kepuasan konsumen menunjukkan nilai positif sebesar 0,457 dengan sig sebesar 0,000, memberikan pengertian bahwa semakin baik servicescape, maka berdampak pada tingginya kepuasan pelanggan terhadap produk tersebut.

c. Nilai koefisien regresi untuk variabel kualitas pelayanan terhadap loyalitas pelanggan menunjukkan nilai positif sebesar 0,210 dengan sig sebesar 0,024, memberikan pengertian bahwa semakin baik kualitas pelayanan, maka berdampak pada tingginya loyalitas pelanggan terhadap produk tersebut.

d. Nilai koefisien regresi untuk variabel servicescape terhadap loyalitas pelanggan menunjukkan nilai positif sebesar 0,198 dengan sig sebesar 0,040, memberikan pengertian bahwa semakin baik servicescape, maka berdampak pada tingginya loyalitas pelanggan terhadap produk tersebut.

e. Nilai koefisien regresi untuk variabel kepuasan konsumen terhadap loyalitas pelanggan menunjukkan nilai positif sebesar 0,401 dengan sig sebesar 0,000, 


\section{Marno Nugroho}

\section{Sahrul Romadhon}

memberikan pengertian bahwa semakin besar kepuasan pelanggan, maka berdampak pada tingginya loyalitas pelanggan terhadap produk tersebut.

\section{Simpulan}

a. Kualitas layanan memiliki pengaruh yang positif dan signifikan terhadap kepuasan Pelanggan. Pelayanan yang berkualitas akan memberikan kepuasan Pelanggan yang lebih tinggi.

b. Servicescapememiliki pengaruh yang positif dan signifikan terhadap kepuasan Pelanggan. Servicescapeyang baik akan memberikan kepuasan Pelanggan yang lebih tinggi.

c. Kualitas pelayanan memiliki pengaruh yang positif dan signifikan terhadap Loyaltas Pelanggan Pelanggan. Pelayanan yang berkualitas akan memberikan Loyaltas Pelanggan Pelanggan yang lebih tinggi.

d. Servicescapememiliki pengaruh yang positif dan signifikan terhadap Loyaltas Pelanggan Pelanggan. Servicescapeyang baik akan memberikan Loyaltas Pelanggan yang lebih besar.

e. Kepuasan pelanggan memiliki pengaruh yang positif dan signifikan terhadap Loyaltas Pelanggan pelanggan. Kepuasan yang besar dari Pelanggan akan memberikan Loyaltas Pelanggan yang lebih besar.

\section{Implikasi Manajerial}

Hasil penelitian mendapatkan bahwa kepuasan yang dirasakan menjadi faktor yang dominan dalam mempengaruhi Loyaltas Pelanggan. Untuk itu kesebandingan nilai dengan pengorbanan pelanggan yang dirasakan perlu untuk terus dioptimalkan. Untuk itu hal ini terkait dengan kualitas perbaikan yang diselesaikan oleh pihak toko untuk selalu memberikan perhatian untuk dapat memberikan nilai tambah bagi Pelanggan. Selain itu pihak toko jam juga harus mengutamakan konsep pelayanan yang memberikan rasa bangga sehingga dapat menanamkan rasa kepercayaan di benak para Pelanggannya.

Servicescape oleh perusahaan juga menjadi variabel yang berpengaruh signifikan terhadap kepuasan maupun Loyaltas Pelanggan. Dengan demikian penciptaan lingkungan dan suasana toko yang baik dapat menjadi fokus yang harus diperhatikan toko. Dengan mendesain dan merancang lingkungan toko menjadi lebih menarik, dapat mempertahankan hasrat untuk membeli produk pada toko jam di Kota Semarang.

Perhatian personal pada Pelanggan harus selalu ditekanan untuk diberikan oleh karyawan toko jam di Kota Semarang. Dengan adanya perhatian lebih dari pihak toko terhadap pelanggan, diharapkan dapat menciptakan kesan nyaman dan aman dibenak pelanggan 
kepada toko jam tersebut. Sehingga dapat mempengaruhi tingkat loyalitas pelanggan terhadap toko jam di Kota Semarang.

\section{DAFTAR PUSTAKA}

Cempaka, Pramita, \& DH Kadarisma Hidayat. 2015. Pengaruh Servicescape (Lingkungan Layanan) Terhadap Kepuasan dan Sampaknya Pada Loyalitas Nasabah. Jurnal Administrasi Bisnis (JAB) 26(2).

Ernani Hadiyanti. 2010. "Analisis Kualitas Pelayanan dan Pengaruhnya Terhadap Loyalitas Pelanggan". Fakultas Ekonomi Universitas Jambi. 2(2): 81-90

Hurriyati, Ratih. 2010. Bauran Pemasaran dan Loyalitas Konsumen. Bandung: ALFABETHA.

Lovelock, Christopher, Jochen, Wirtz, \& Jacky, Mussry. 2011. Pemasaran Jasa. edisi 7. Erlangga: Jakarta

Lumentut L.F. dan Palandeng I.D. 2014. "Studi Mengenai Fasilitas, Servicescape, dan Kualitas Pelayanan, Pengaruhnya Terhadap Kepuasan Konsumen McDonald's Manado". Jurnal EMBA, Vol. II, No. 3, 126-136.

Lupiyoadi, Rambat. 2013. Manajemen Pemasaran Jasa Berbasis Kompetensi (Edisi 3). Jakarta: Salemba Empat.

Kotler, Philips \& Armstrong .2016. Marketing Management, 15 th Edition. New Jersey: Pearson Prentice Hall.

Masloman, Lumanauw, dan Trang. 2014. "Studi mengenai Kualitas Pelayanan dan Servicescape Pengaruhnya Terhadap Kepuasan Konsumen (Studi Kasus pada Kentucky Fried Chicken di Multimart Ranotana Manado)". Jurnal EMBA 2(4): 589601.

Musriha. 2011. "Pengaruh Servicescape dan Kualitas Komunikasi Karyawan Terhadap Loyalitas Nasabah Melalui Kepuasan Nasabah Bank Mandiri di Surabaya". Ekuitas 5(2): 257-268.

Pangkey T. P. 2013. "Analisis Servicescape Terhadap Loyalitas Pengunjung pada Hotel Berbintang di Manado (Studi pada Hotel Quality Manado)". Jurnal EMBA 1 (3): 233241. 
Marno Nugroho

Sahrul Romadhon

Ratminto dan Winarsih A. S. 2012. Manajemen Pelayanan : Pengembangan Model Konseptual, Penerapan Citizen's Charter dan Standar Pelayanan Minimal, Jakarta. Pustaka Pelajar.

Rismi Somad dan Juni Priansa Donni. 2014. Manajemen Komunikasi: Mengembangkan Bisnis Berorientasi Pelanggan. Jakarta. Prenhallindo.

Sugiyono. 2001. Metode Penelitian. Bandung: CV Alfa Beta.

Tjiptono. Fandy dan Gregorius Chandra. 2012. Pemasaran Strategik. Yogyakarta. Andi

Yulianita G. A., Gitasiswara. 2013. "Pengaruh Servicescape Terhadap Loyalitas Tamu Mancanegara di Alam Kulkul Boutique Resort Bali". Tourism and Hospitality Essentials Journal (THE Journal 3(1): 574-560. 